OPEN ACCESS

Edited by:

Luisa Galgani,

University of Siena, Italy

Reviewed by:

Riaan Van Der Merwe,

Petroleum Institute,

United Arab Emirates

Dick Vethaak

Deltares, Netherlands

André Ricardo de Araújo Lima,

Federal Rural University of

Pernambuco, Brazil

${ }^{*}$ Correspondence:

Elisa Marti

elisa.marti@uca.es

Specialty section:

This article was submitted to

Marine Pollution,

a section of the journal

Frontiers in Marine Science

Received: 17 July 2017 Accepted: 06 October 2017 Published: 08 November 2017

Citation:

Martí E, Martin C, Cózar A and Duarte CM (2017) Low Abundance of

Plastic Fragments in the Surface

Waters of the Red Sea.

Front. Mar. Sci. 4:333.

doi: 10.3389/fmars.2017.00333

\section{Low Abundance of Plastic Fragments in the Surface Waters of the Red Sea}

\author{
Elisa Martí ${ }^{*}$, Cecilia Martin ${ }^{2}$, Andrés Cózar ${ }^{1}$ and Carlos M. Duarte ${ }^{2}$ \\ ${ }^{1}$ Departamento de Biología, Campus de Excelencia Internacional del Mar, Instituto Universitario de Investigaciones Marinas, \\ Universidad de Cádiz, Puerto Real, Spain, ${ }^{2}$ Biological and Environmental Science and Engineering Division, Red Sea \\ Research Center, King Abdullah University of Science and Technology, Thuwal, Saudi Arabia
}

The floating plastic debris along the Arabian coast of the Red Sea was sampled by using surface-trawling plankton nets. A total of 120 sampling sites were spread out over the near-shore waters along $1,500 \mathrm{~km}$ of coastline during seven cruises performed during 2016 and 2017. Plastic debris, dominated by millimeter-sized pieces, was constituted mostly of fragments of rigid objects (73\%) followed by pieces of films (17\%), fishing lines (6\%), and foam (4\%). These fragments were mainly made up by polyethylene (69\%) and polypropylene (21\%). Fibers, likely released from synthetic textiles, were ubiquitous and abundant, although were analyzed independently due to the risk of including non-plastic fibers and airborne contamination of samples in spite of the precautions taken. The plastic concentrations (excluding possible plastic fibers) contrasts with those found in other semi-closed seas, such as the neighboring Mediterranean. They were relatively low all over the Red Sea ( $<50,000$ items km$~^{-2}$; mean $\pm \mathrm{SD}=3,546 \pm 8,154$ plastic item $\mathrm{km}^{-2}$, $1.1 \pm 3.0 \mathrm{~g} \mathrm{~km}^{-2}$ ) showing no clear spatial relationship with the distribution of coastal population. Results suggests a low plastic waste input from land as the most plausible explanation for this relative shortage of plastic in the surface waters of the Red Sea; however, the additional intervention of particular processes of surface plastic removal by fish or the filtering activity of the extensive coral reefs along the coastline cannot be discarded. In addition, our study highlights the relevance of determining specific regional conversion rates of mismanaged plastic waste to marine debris, accounting for the role of near-shore activities (e.g., beach tourism, recreational navigation), in order to estimate plastic waste inputs into the ocean.

\section{Keywords: plastic fragments, Red Sea, Mediterranean Sea, Côte d'Azur, surface waters}

\section{INTRODUCTION}

Efforts to assess the global distribution of marine floating plastic debris over the last years are now allowing for a comprehensive depiction of global patterns. High plastic accumulation zones were hypothesized, and confirmed, in each of the five subtropical gyres (Law et al., 2010; Goldstein, 2012; Cózar et al., 2014), and semi-enclosed systems, such as the Mediterranean (Cózar et al., 2015; Ruiz-Orejón et al., 2016; Suaria et al., 2016) and the Arctic Ocean (Cózar et al., 2017), which has been equated to a "polar Mediterranean" because of being surrounded by continents and linked to global ocean circulation through terminal surface currents (Aagaard et al., 1985; Østerhus et al., 2005). However, extensive areas remain yet unexplored, particularly semi-enclosed basins highly susceptible to accumulate plastic because of the limited hydrodynamic capacity to transfer the 
inputs they receive from land or import through ocean circulation into the open ocean. This is the case for the Red Sea, spreading over $438,000 \mathrm{~km}^{2}$ in one of the world's warmest regions.

The Red Sea is characterized by low annual rainfall, the absence of permanent rivers in its catchment area and high evaporation. In the north, the artificial canal in the Gulf of Suez opens an important shipping route connecting the Mediterranean to the Red Sea. In the south, the Red Sea connects to the Indian Ocean through the strait of Bab el Mandab, importing the Indian Ocean into the Red Sea at the surface and exporting hypersaline Red Sea water at depth (Smeed, 2004). Maritime traffic is intense along the Red Sea, one of the major shipping routes for oil tankers and merchant vessels in the ocean (Gladstone et al., 1999). The shoreline is sparsely populated, with Jeddah (Kingdom of Saudi Arabia) being the only human settlement above 150,000 inhabitants along the extensive Saudi coast spanning the entire Eastern margin of the Red Sea. The Red Sea is largely a coastal ocean, with a deep (up to 2,800 m) central zone and extensive shallow areas supporting mangroves, seagrass beds and one of the most extensive coral reef systems in the world (Bruckner et al., 2012; Figure 1).

The Red Sea basin, like the Mediterranean, shows an inverse estuarine circulation driven by high evaporation in the basin, with the water exchange with the Indian Ocean defined by a surface inflow of low-salinity water over a deeper outflowing high-salinity water layer (Cessi et al., 2014). This dominant twolayer transport is replaced between June and September by a three-layer exchange comprised of a shallow surface outflow, an intermediate intrusion of the relatively fresh and cold Gulf of Aden water and a deep hypersaline outflow (Sofianos, 2002). This hydrodynamic pattern implies a limited capacity to export floating debris from the Red Sea and a more likely import from the Indian Ocean, suggesting that the Red Sea may act as a trap for floating plastic pollution, as reported for the Mediterranean Sea (Cózar et al., 2015). On the other hand, the Mediterranean Sea and the Red Sea show also relevant dissimilarities in relation to coastal population levels, touristic activity or biological communities, which may affect the input and loads of plastic pollution.

Here, we assessed, for the first time, the load and distribution of floating plastic litter across the Red Sea, with a focus on the Eastern half, encompassing the Economic Exclusive Zone (EZZ) of Saudi Arabia. Our aim was to examine the occurrence, composition and distribution of plastic debris in the surface waters and, by using other world seas and particularly the Mediterranean Sea as reference, to characterize its pollution level and possible sources.

\section{MATERIALS AND METHODS}

A total of 120 samples were collected during 7 cruises on board KAUST R/V Thuwal covering 1,500 km of the Arabian coastline of the Red Sea. During 2016, 95 samples were collected during five cruises from February 17th to December 1st and 25 additional samples were collected during two cruises from
March 1st to April 6th 2017 (Table S1). Plastic debris was sampled following standard procedures, similar to those used in the assessment of plastic pollution in the Mediterranean Sea (Cózar et al., 2015), by using a manta trawl $(0.5 \times$ $0.15-\mathrm{m}$ mouth, $150-\mu \mathrm{m}$ mesh). The net was towed at the top $10 \mathrm{~cm}$ of the sea surface with an average speed of 2.5 knots during 15-30 min. The material collected by the net was mixed with $0.2-\mathrm{mm}$-filtered seawater and floating plastic debris was carefully picked out from the water surface with the aid of a stereoscopic microscope in the laboratory. This examination was repeated to ensure the detection of the smallest particles, isolating separately plastic items and fibers. Plastic items were extracted from the seawater samples and washed and dried at room temperature, whereas the materials identified as possible plastic fibers found in the samples were counted and analyzed independently. Rigorous precaution was taken during the sample processing, using cleaned instruments and blanks from sampling operations until the end of the sorting at the laboratory.

Plastic items were counted, photographed and processed to measure each item using ImageJ Software (http://imagej.nih. gov). They were classified into four size intervals: $0.2-0.5,0.5-$ $1,1-5$, and $5-500 \mathrm{~mm}$ (width of the net mouth). To render plastic counts per bin independent of the width of the bin, the abundance of plastic items for each bin was normalized by dividing them by the size interval width (Cózar et al., 2014). In addition, plastic items were classified according to aspect and consistency in rigid fragments (hard pieces from broken objects); films (bags, wrappings, or pieces of them); fishing lines (including those released from nets); foamed plastic; pellets (raw form of plastic) and beads (possibly derived from products for cleansing and personal care).

To confirm the plastic nature of the material collected in the examinations, Fourier transform infrared spectrometry (Nicolet 10 FT-IR for particles $\geq 250 \mu \mathrm{m}$ and Nicolet $6700 \mu$ FT-IR coupled with a microscope for particles $<250 \mu \mathrm{m}$ ) was applied to a random subset of items $(n=198)$. Thirty-two scans at medium resolution were performed per item. Wave number ranged between 4,000 and $650 \mathrm{~cm}^{-1}$ and the spectra were verified using the OMNIC Spectra Library. Unfortunately, this could not be applied to items identified as possible fibers, as this FTIR testing of this particular type of debris requires a Diamond Compression cell, which was not available. Hence, plastic fibers are reported separately, as their identification has not been confirmed and remains putative.

The area sampled in each net tow was estimated from the product of trawling length (from GPS positions) and width of the net. Given the effect of wind mixing on the vertical distribution of buoyant plastic debris, the wind correction proposed by Kukulka et al. (2012) was applied to the net tows carried out with average friction velocity in water $\left(\mathrm{u}^{*}\right)>0.6(30.8 \%$ of the tows). Differences in wind speed among the seven surveys were statistically tested with the non-parametric Kruskal-Wallis test.

The population within the $50-\mathrm{km}$ coastal strip of the Red Sea was estimated from gridded global population data from the 2008 LandScan data set (http://web.ornl. gov/sci/landscan/datasets/LS2008.ris). The linear distance from 


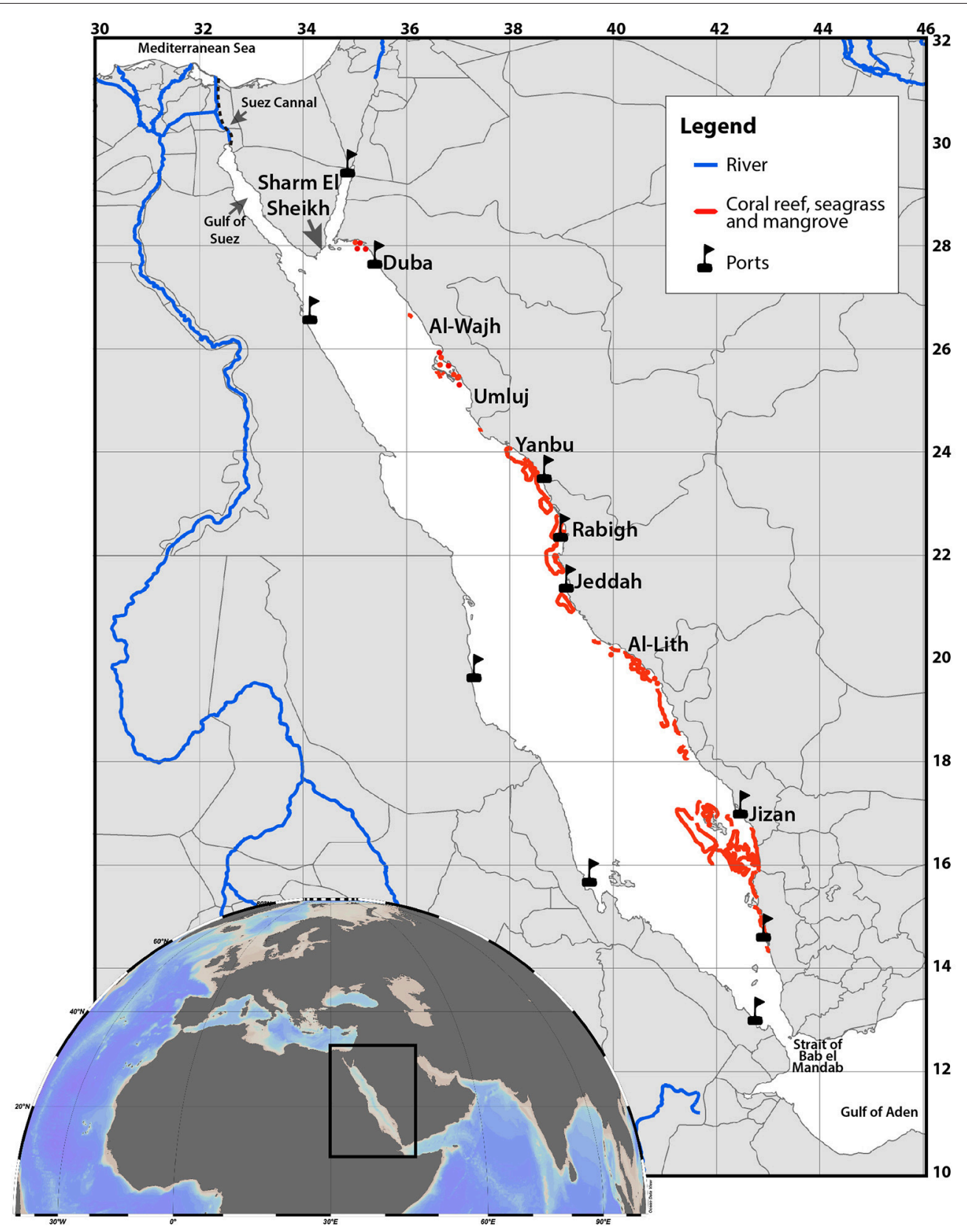

FIGURE 1 | Geographic location of the study area. Blue lines show rivers, red lines indicate coral reefs, seagrass beds and mangroves, and black flags are major ports (Adapted from Natural Earth and Bruckner et al., 2012).

Sharm El Sheikh, at the northernmost part of the Red Sea, was used as a reference to analyze the distribution of plastic and population along the Red Sea. Data on floating plastic abundance and population was aggregated into 29 bins of 50$\mathrm{km}$ length each along the north-south transect (1,400 km long). The relationship between these variables was explored using Spearman's correlation in the R statistical package.

Plastic concentrations in the Red Sea and Mediterranean Sea were compared using a non-parametric Mann-Whitney $U$-test. Likewise, plastic concentration in relation to the distance to land was analyzed using different distance bins and compared to plastic abundances measured in the Côte d'Azur (French Mediterranean coast) (Pedrotti et al., 2016). To allow this comparison, sampling sites in the Red Sea $(n=120$, distance from land: $0.17-151 \mathrm{~km})$ and the Mediterranean Sea $(n=70$, $0.3-340 \mathrm{~km}$ ) were grouped into four logarithmic bins of distance to shore $(0.1-1,1-10,10-100$, and $100-1,000 \mathrm{~km})$. A nonparametric Kruskal-Wallis test was used to test for significant differences in floating plastic fragment abundance between distance bins. 


\section{RESULTS}

Plastic fragments were found in $60.8 \%$ of the samples, with a total of 298 plastic items (excluding fibers) found in the 120 stations sampled during the seven cruises carried out across the Red Sea. The concentrations of plastic fragments were generally low, ranging from 0 to 50,393 item $\mathrm{km}^{-2}$ (Figure 2A), with an average $\pm \mathrm{SD}$ concentration of $3,546 \pm 8,154$ plastic item $\mathrm{km}^{-2}$ (median $=1,030$ items $\mathrm{km}^{-2}$, cf. Table $\mathbf{1}$ for concentration per unit volume). The mass concentration of plastic fragments ranged from 0 to $22 \mathrm{~g} \mathrm{~km}^{-2}$ (median $=0.03 \mathrm{~g} \mathrm{~km}^{-2}$, mean $\pm \mathrm{SD}$ $=1.1 \pm 3.0 \mathrm{~g} \mathrm{~km}^{-2}$ ). The highest plastic fragment concentration was sampled around $300 \mathrm{~km}$ South of Sharm El Sheikh (Figure 2D).

Possible plastic fibers were found in all samples. However, despite all precautions, blank controls showed between 0 and 3 possible plastic fibers, highlighting the high risk of contamination of samples by fibers. After subtracting the fibers in the blank controls from that in the corresponding samples, the concentration of possible plastic fibers ranged between 9 and 222,838 fibers $\mathrm{km}^{-2}$ (median $=25,110$ fibers $\mathrm{km}^{-2}$, mean \pm $\mathrm{SD}=32,703 \pm 30,208$ fibers $\mathrm{km}^{-2}$ ) (Figure 2B). These items were the most abundant and prevalent (Figure 2C) although they were not combined with the estimate of the load of plastic debris in the Red Sea due to uncertainties as to the plastic nature of these fibers, which could not be verified. Nevertheless, because of the low mass of the fibers (about $0.002 \mathrm{mg} \mathrm{fiber}^{-1}$ assuming an average plastic density, $1.6 \mathrm{~g} \mathrm{~cm}^{-3}$, Hidalgo-Ruz et al., 2012), its contribution to the total plastic mass would be minimal $(<7 \%)$ even if all possible plastic fibers would be included.

Coastal population is relatively low along the Arabian coast, except for the human settlement of Jeddah, accounting for almost $74 \%$ of the total coastal population in the East coast of the Red Sea (Figure 2D), but we found no clear relationship between plastic concentration and population, either for plastic fragments $(r=-0.19, p=0.30, n=29)$ or possible plastic fibers $(r=0.34$, $p=0.06, n=29$ ).

In relation to plastic categories, rigid fragments were the most abundant items (73\%), followed by pieces of films (17\%), fishing lines (6\%), and foam (4\%) (Figure 3A). Neither pellets nor beads were found in the samples. Thus, we will refer to these plastic categories (pieces of rigid objects, films, fishing lines, and foam) as plastic fragments, in contrast to fibers. Fourier Transform infrared (FT-IR) micro spectroscopy confirmed the plastic identity of all particles analyzed. Most of the plastic items were polyethylene (PE, 69\%), followed by polypropylene (PP, $21 \%$ ), polystyrene (PS, 4\%), polyvinyl chloride (PVC, 3\%) and polyurethane (PU, $1 \%)$, cellophane $(\mathrm{CP}, 1 \%)$ and polyamide (PA, 1\%) (Figure 3B). The predominance of $\mathrm{PE}$ and $\mathrm{PP}$, accounting for $90 \%$ of the total plastic, is in close agreement with the dominance of these materials in floating plastic fragments reported for the Mediterranean Sea (Suaria et al., 2016).

The mean length of the plastic items was $2.08 \pm 2.74 \mathrm{~mm}$, ranging from 0.26 to $29.67 \mathrm{~mm}$. The low number of plastic items collected only allowed the use of four size bins to analyse the plastic size distribution, in contrast with narrower size classes allowed by the larger number of items obtained in previous studies (Cózar et al., 2014, 2015, 2017). Once the plastic abundances were normalized by the width of the size bins, the highest abundance appeared in the size range between 0.5 and $1 \mathrm{~mm}(55.1 \%)$ (Figure 3C).

Kruskal-Wallis tests indicated that there were statistically significant differences in wind speeds between the surveys likely due to seasonal variability between months of sampling (KruskalWallis test, $p<0.001$ ). However, there were no statistically significant differences in abundance of plastic fragments nor possible plastic fibers between the seven surveys (KruskalWallis test, $p=0.19$ for plastic items and $p=0.48$ for fibers).

The comparison of plastic fragment concentrations in the Mediterranean Sea and Red Sea showed significant differences (Mann-Whitney, $p<0.001$ ), with the concentration in the Red Sea being two orders of magnitude lower than that in the Mediterranean Sea (Figure 4). However, we did not observe significant variation in plastic abundance in the Red Sea between water strips to land (Kruskal-Wallis test, $p=0.4$ ).

\section{DISCUSSION}

The concentration of plastic debris found in the surface waters of the Red Sea is the lowest thus far reported for a coastal sea (Table 1). The average concentration of plastic items (excluding fibers) in the Eastern Red Sea was $1.08 \mathrm{~g} \mathrm{~km}^{-2}$, two orders of magnitude below the concentrations measured using comparable sampling methods in in the Mediterranean Sea (range 423-672 $\mathrm{g} \mathrm{km}^{-2}$, Cózar et al., 2015; Ruiz-Orejón et al., 2016; Suaria et al., 2016), and comparable to that in the areas with the lowest plastic loads in the global open ocean (Cózar et al., 2014; Table 1).

There are two reasons, not mutually exclusive, that may explain such low abundance of floating plastic fragments in the semi-enclosed Red Sea, (1) low inputs of plastic waste into the Red Sea; and/or (2) fast removal rates of plastic debris from the surface. The average number of inhabitants per linear kilometer settled on Arabian coast is $4,100 \mathrm{~km}^{-1}$, whereas the Côte d'Azur (in the French Mediterranean coast) supports 10,300 inhabitants per linear kilometer (http://web.ornl.gov/sci/ landscan/), which is consistent with the difference in plastic load between these two areas (Figure 4). Indeed, the lack of a significant correlation between the concentration of floating plastic fragments and population along the Red Sea is in contrast with the correlation found by Pedrotti et al. (2016) in the Côte d'Azur, where there was a more even distribution of population, with several large coastal cities, such as Toulon, Nice, Monaco, or Genova.

In addition, the lack of rivers discharging in the Red Sea may also lead to low inputs, as rivers are major conduits for plastic inputs into the ocean (Lebreton et al., 2017). However, waste management remains an unresolved problem in the Red Sea region (Gladstone et al., 1999). Using the estimates of mismanaged plastic waste per person for Saudi Arabia and France by Jambeck et al. (2015), the total amount of mismanaged plastic waste was estimated to be higher in the Red Sea, at 

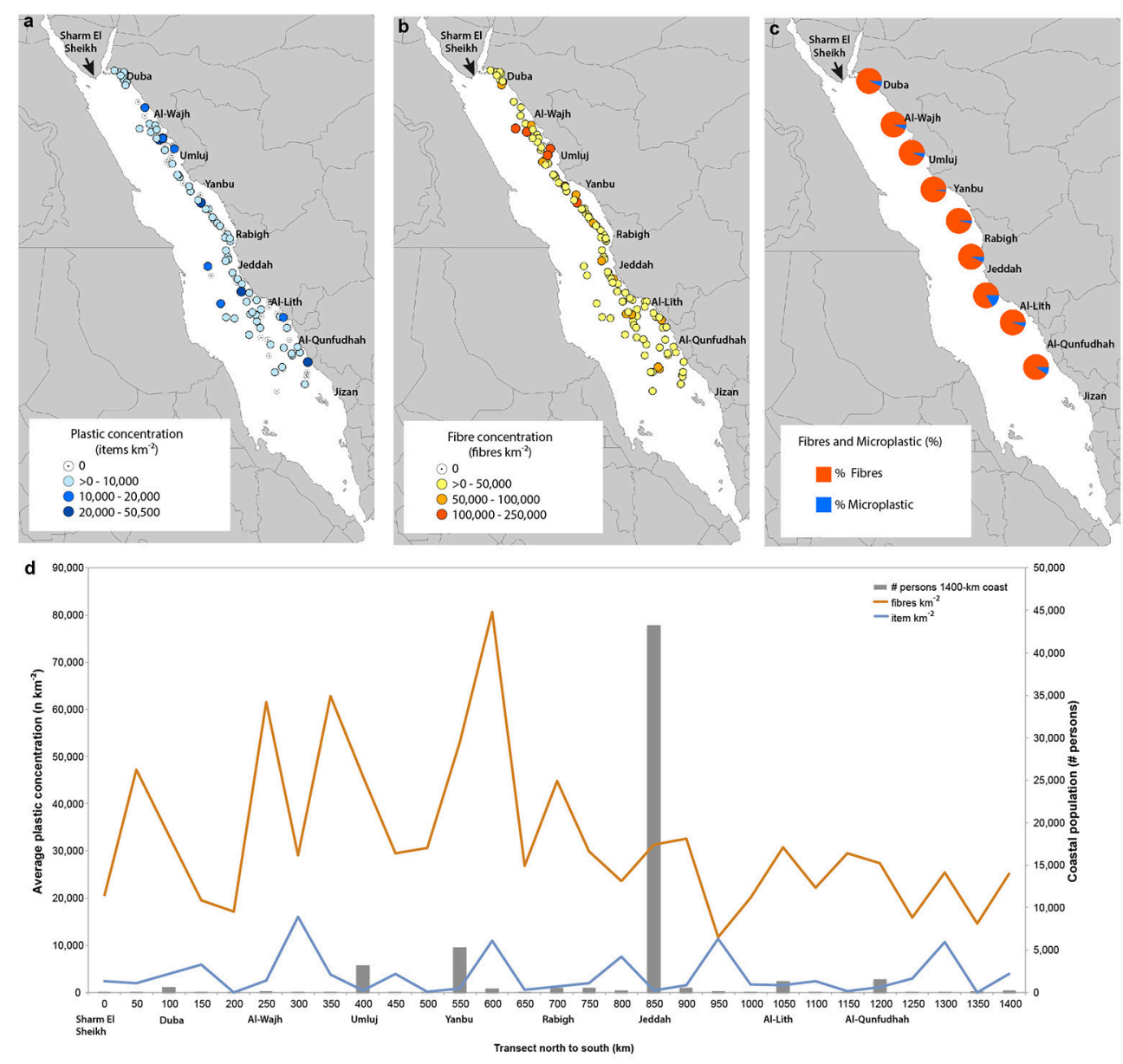

FIGURE 2 | Concentration of plastic fragments (A) and possible plastic fibers (B) in the 120 sampling sites. Average percentage of plastic fragments and possible plastic fibers along the Red Sea transect (C). Coastal population (gray bars), plastic concentrations (blue line), and possible plastic fibers (orange line) in relation to the linear distance from Sharm El Sheikh $(0 \mathrm{~km})$, at the northernmost part of the Red Sea (D).

23.7 tons $\mathrm{km}^{-1}$ year ${ }^{-1}$ for the Arabian coast, than for the Côte d'Azur, with 14.4 tons $\mathrm{km}^{-1}$ year ${ }^{-1}$, which contrasts with the concentrations of floating plastic debris measured in the waters. The explanation for this mismatch could be related to important differences in the transfer of mismanaged plastic waste from land to sea and/or a higher loss rate of floating plastic. First, the efficiency of this transfer in the Arabian coast and the Côte d'Azur may differ because of the absence of rivers in the Red Sea, which possibly accounts for part of the differences found in floating plastic pollution. In addition, near-shore activities, such as beach tourism, cruises and recreational navigation are far more intense in the Côte d'Azur, which experiences a large increase in summer population and waste generation on the coasts, than in the Arabian coast of the Red Sea, where coastal tourism is virtually absent. The monitoring of beach debris in the Mediterranean Balearic Islands demonstrated the importance of near-shore activities associated with summer coastal tourism in the abundance and composition of the waste stranded on beaches (Martinez-Ribes et al.,
2007), which has high probability to become marine floating debris.

Provided the lack of rivers in the Red Sea, wind could play a major role in transporting plastic waste from land into the sea, which would be most effective in delivering fibers and light filmtype objects, such as wrappings and bags. Indeed, this typology of light debris was relatively abundant in Red Sea surface waters. The concentration of possible plastic fibers was comparable to that reported for other ocean regions (Setälä et al., 2016), with fibers representing, numerically, 92\%, on average of the total number of possible plastic items (Figure 2C). The typology of the floating plastic fragments (hard pieces, films, lines, and foam) showed a proportion of $17 \%$ of films in abundance, which is in the upper range of the proportion of film reported in assessment of floating plastic litter in the Mediterranean Sea (range from 1 to 6\%, Cózar et al., 2015; Suaria et al., 2016; Van der Hal et al., 2017).

Surface losses of plastic may be related to multiple processes. Shore deposition, nano-fragmentation, ingestion by marine 
TABLE 1 | Comparison of floating plastic fragment concentrations (listed by increasing number) obtained in previous studies performed in the open ocean and other semi-closed seas and those derived here for the Red Sea.

\begin{tabular}{|c|c|c|c|c|c|c|}
\hline & $\begin{array}{c}\text { Average } \\
\text { abundance } \\
\text { (items } \text { km }^{-2} \text { ) }\end{array}$ & $\begin{array}{c}\text { Average } \\
\text { abundance } \\
\text { (items } \mathrm{m}^{-3} \text { ) }\end{array}$ & $\begin{array}{c}\text { Maximum } \\
\text { abundance } \\
\text { (items } \mathrm{km}^{-2} \text { ) }\end{array}$ & $\begin{array}{l}\text { Average } \\
\text { weight } \\
\left(\mathrm{g} \mathrm{km}^{-2}\right)\end{array}$ & $N$ & Source \\
\hline Red Sea & 3,546 & 0.04 & 50,393 & 1.1 & 120 & This study \\
\hline $\begin{array}{l}\text { Open Ocean: } \\
\text { non-accumulation zones }\end{array}$ & 7,894 & 0.05 & 190,000 & 21 & 629 & Cózar et al., 2017 \\
\hline Baltic Sea & 14,667 & 0.09 & 48,000 & ND & 12 & Setälä et al., 2016 \\
\hline Greenland and Barents Seas & 80,796 & 0.54 & 317,000 & 99 & 17 & Cózar et al., 2017 \\
\hline Mediterranean Sea & 147,500 & 0.59 & $1,164,403$ & 579 & 71 & Ruiz-Orejón et al., 2016 \\
\hline $\begin{array}{l}\text { Open Ocean: subtropical } \\
\text { accumulation zones }\end{array}$ & 155,389 & 1.04 & $1,260,000$ & 407 & 275 & Cózar et al., 2017 \\
\hline Mediterranean Sea & 195,510 & 1.96 & 576,555 & ND & 33 & Pedrotti et al., 2016 \\
\hline Mediterranean Sea & 243,853 & 0.49 & $1,224,084$ & 423 & 39 & Cózar et al., 2015 \\
\hline Mediterranean Sea & 382,400 & 0.76 & $4,321,120$ & 672 & 74 & Suaria et al., 2016 \\
\hline Mediterranean Sea & $1,518,340$ & 7.68 & $64,812,600$ & ND & 17 & Van der Hal et al., 2017 \\
\hline East Asian Seas & $1,720,000$ & 3.70 & ND & ND & 56 & Isobe et al., 2015 \\
\hline
\end{tabular}

All plastic concentrations exclude fibers.

\section{A}
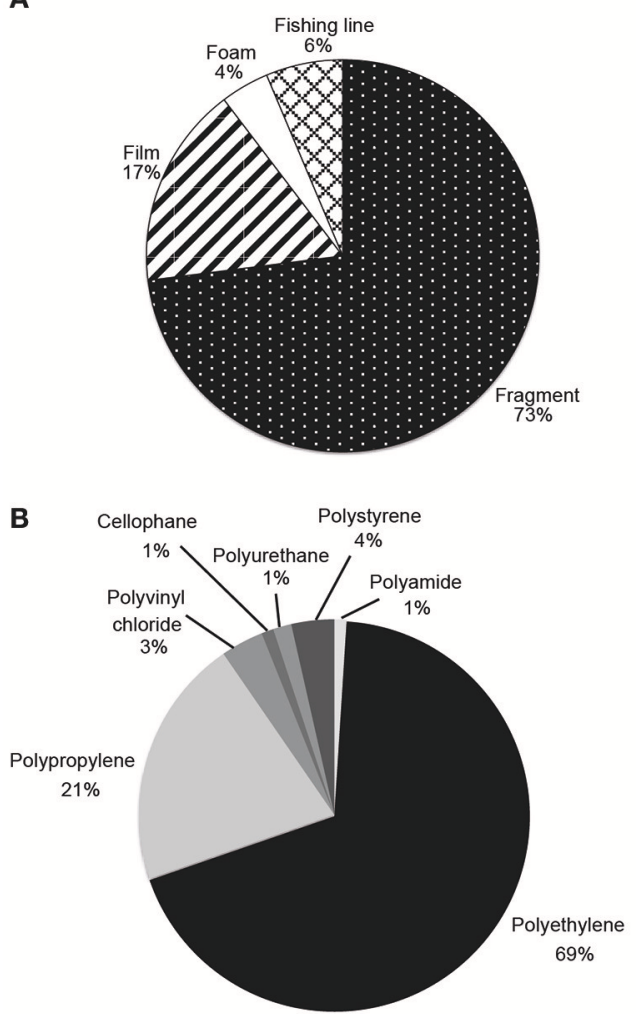
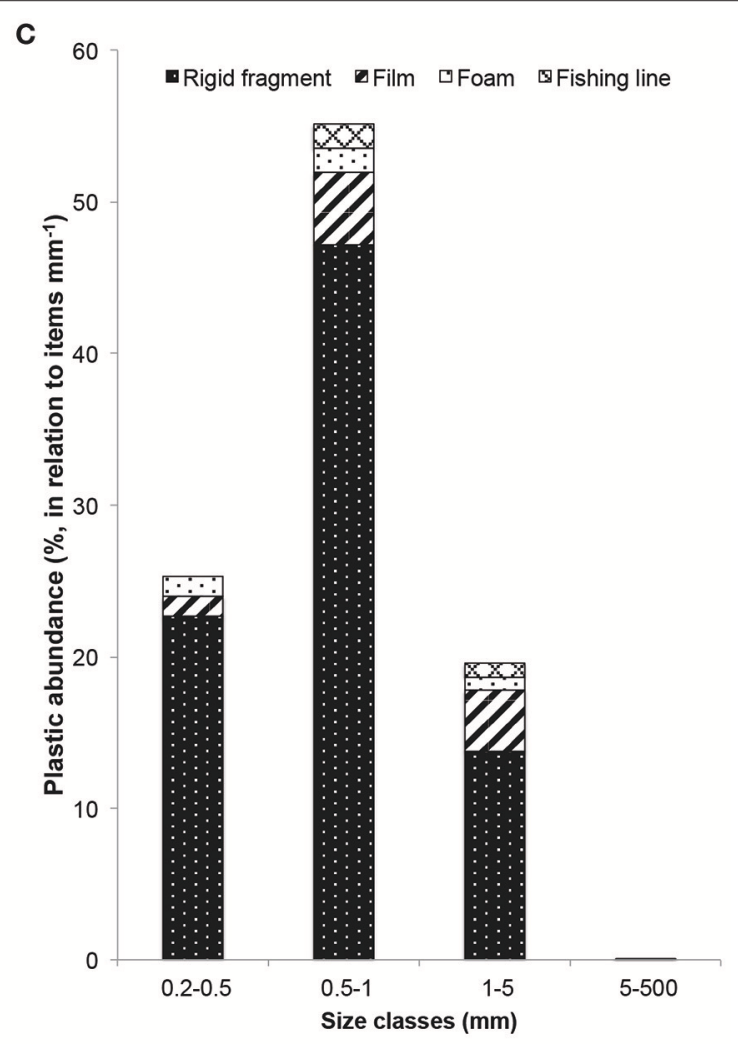

FIGURE 3 | Frequency of occurrence of plastic items by category (A) and type (B), and relative abundance of plastic items per size classes and category (C). Please note that fibers are excluded because just fragments of rigid objects, films, fishing lines, and foam could be tested through FT-IR spectroscopy.

organism, or sinking by aggregation or ballasting due to epiphytic growth are some of the general pathways suggested as conduits of plastic debris from the surface waters to coast (Cózar et al., 2014). Here, we limit our discussion on the surface losses of plastic to suggest some processes that could operate with particular intensity in the Red Sea. Firstly, the presence of mangroves and extensive coral reefs is an additional feature that differentiates Arabian coast of the Red Sea from that of the Mediterranean. 


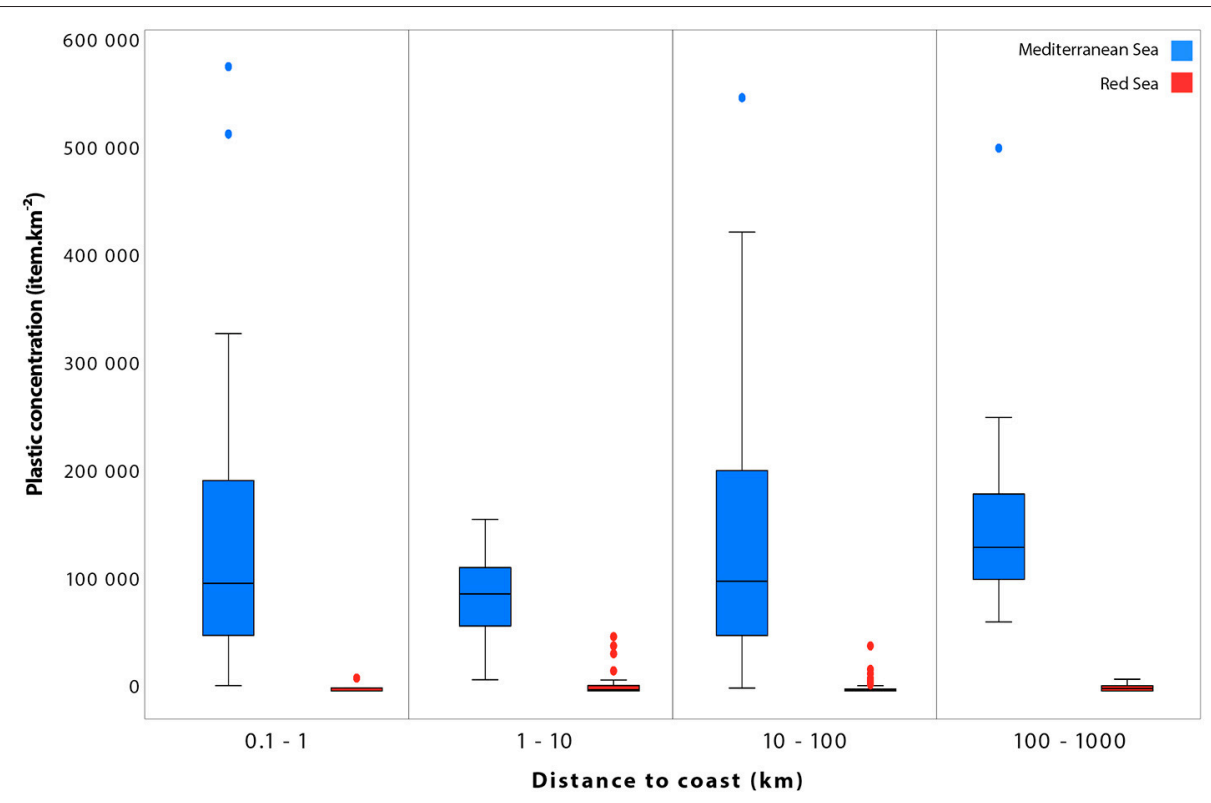

FIGURE 4 | Comparison between floating plastic concentrations in Mediterranean (blue) and Red Sea (red) for different water strips from land (0.1-1, 1-10, 10-100, and 100-1,000 km). Data from the Mediterranean are described in Pedrotti et al. (2016). The Mediterranean water strips close to land (<10 km to land) mainly accounts for the Côte d'Azur in France. Black lines into the boxes indicate median values, boxes indicate first and third quartiles, and whiskers indicate the 90 and 10th percentiles.

Mangroves have been reported to act as traps for microplastics in Brazil and Singapore (Ivar do Sul et al., 2014; Nor and Obbard, 2014). Therefore, mangroves could be trapping part of the waste transported by the occasional rainfall events as well as marine debris stranded on the coasts during storm events. Although we do not have quantitative information on plastic waste in Red Sea mangroves, macro-debris was commonly observed in these coastal ecosystems during our surveys. The extensive coral reefs along the coast of the Red Sea (Figure 1), which act as large filters of particulate materials, may also act as important microplastic sinks. Indeed, numerous coral-reef inhabitants, including the corals themselves, efficiently capture bacteria, phytoplankton, zooplankton and small-sized detritus in the water advected over the reefs (Tranter and George, 1969; Yahel et al., 1998; Houlbreque and Ferrier-Pages, 2009). Although the studies of plastic ingestion in corals are yet very scarce, researchers recently demonstrated that scleractinian corals do capture and ingest microplastics, from 0.1 to $2 \mathrm{~mm}$ in length (Hall et al., 2015), and from 0.125 to $1 \mathrm{~mm}$ (Allen et al., 2017); matching the size range of plastic debris reported in our assessment. Mesopelagic fish assemblages have also been reported to be relevant feeders of plastic fragments in the size interval from 0.5 to $5 \mathrm{~mm}$ (Boerger et al., 2010; Davison and Asch, 2011; Foekema et al., 2013), and are especially abundant in the Red Sea, with nocturnal feeding migration to the surface particularly active in comparison with other world regions (Dypvik and Kaartvedt, 2013). Other important consumers may include seabirds and turtles, which are abundant in the Red Sea. The size distribution of floating plastic debris found in the Red Sea, with a drop in abundance toward the smallest sizes, is consistent with the hypothesis of an efficient biological removal of small plastic particles (Cózar et al., 2014), but the role of Red Sea biota, including mangroves, coral ecosystems, mesopelagic fish and other consumers, as sinks for floating plastic debris need yet to be assessed.

Here we show a remarkable low concentration in abundance and weight of plastic fragments in the surface waters of the Red Sea, orders of magnitude below that reported for other semienclosed seas, such as the Mediterranean Sea. Whereas, this may be partially attributable to sporadic surface runoff into the Red Sea and low levels of coastal development and tourism, the poor waste management in the region suggests relatively high inputs. Hence, the exceedingly low floating plastic concentrations in the Red Sea also suggest intense biological removal as an important process in the mass balance conducive to the low loads of plastic fragments that characterize Red Sea waters.

\section{AUTHOR CONTRIBUTIONS}

EM, CM, AC, and CD performed research; EM and CM collected and processed the samples; EM, CM, AC, and CD analyzed data and wrote the paper.

\section{ACKNOWLEDGMENTS}

This work was supported and funded by the King Abdullah University of Science and Technology (KAUST) through the baseline funding to $\mathrm{CD}$, as well as Campus de Excelencia Internacional del Mar (CEIMAR) through a Pre-doctoral Research Project Grant to EM. We thank personnel from R/V 
Thuwal for assistance during samples, Hua Tan at the Analytical Core Lab (KAUST) for access to the FT-IR and technical support, and RSRC colleagues for field assistance. We also have received additional support from PLASTREND (BBVA Foundation) and MIDaS (CTM2016-77106-R, AEI/FEDER/UE) projects.

\section{REFERENCES}

Aagaard, K., Swift, J. H., and Carmack, E. C. (1985). Thermohaline circulation in the Arctic Mediterranean Seas. J. Geophys. Res. 90, 4833-4846. doi: 10.1029/JC090iC03p04833

Allen, A. S., Seymour, A. C., and Rittschof, D. (2017). Chemoreception drives plastic consumption in a hard coral. Mar. Pollut. Bull. doi: 10.1016/j.marpolbul.2017.07.030. [Epub ahead of print].

Boerger, C. M., Lattin, G. L., Moore, S. L., and Moore, C. J. (2010). Plastic ingestion by planktivorous fishes in the North Pacific Central Gyre. Mar. Pollut. Bull. 60, 2275-2278. doi: 10.1016/j.marpolbul.2010.08.007

Bruckner, A., Rowlands, G., Riegl, B., Purkis, S., Williams, A., and Renaud, P. (2012). Khaled Bin Sultan Living Oceans Foundation Atlas of Saudi Arabian Red Sea Marine Habitats. Phoenix, AZ: Panoramic Press.

Cessi, P., Pinardi, N., and Lyubartsev, V. (2014). Energetics of semienclosed basins with two-layer flows at the strait. J. Phys. Oceanogr. 44, 967-979. doi: 10.1175/JPO-D-13-0129.1

Cózar, A., Echevarría, F., González-Gordillo, J. I., Irigoien, X., Úbeda, B., Hernández-León, S., et al. (2014). Plastic debris in the open ocean. Proc. Natl. Acad. Sci. U.S.A. 111, 10239-10244. doi: 10.1073/pnas.1314705111

Cózar, A., Martí, E., Duarte, C. M., García-de-lomas, J., Sebille, E. V., Ballatore, T. J., et al. (2017). The Arctic Ocean as a dead end for floating plastics in the North Atlantic branch of The Thermohaline Circulation. Sci. Adv. 3, 1-8. doi: $10.1126 /$ sciadv. 1600582

Cózar, A., Sanz-Martín, M., Martí, E., González-Gordillo, J. I., Ubeda, B., Gálvez, J. Á., et al. (2015). Plastic accumulation in the Mediterranean Sea. PLoS ONE 10:e0121762. doi: 10.1371/journal.pone.0121762

Davison, P., and Asch, R. G. (2011). Plastic ingestion by mesopelagic fishes in the North Pacific Subtropical Gyre. Mar. Ecol. Prog. Ser. 432, 173-180. doi: $10.3354 /$ meps 09142

Dypvik, E., and Kaartvedt, S. (2013). Vertical migration and diel feeding periodicity of the Skinnycheek lanternfish (Benthosema pterotum) in the Red Sea. Deep Sea Res. I Oceanogr. Res. Pap. 72, 9-16. doi: 10.1016/j.dsr.2012.10.012

Foekema, E. M., De Gruijter, C., Mergia, M. T., vam Franeker, J. A., Murk, A. J., and Koelmans, A. A. (2013). Plastic in North sea fish. Environ. Sci. Technol. 47, 8818-8824. doi: 10.1021/es400931b

Gladstone, W., Tawfiq, N., Nasr, D., Andersen, I., Cheung, C., Drammeh, H., et al. (1999). Sustainable use of renewable resources and conservation in the Red Sea and Gulf of Aden: issues, needs and strategic actions. Ocean Coast. Manage. 42, 671-697. doi: 10.1016/S0964-5691(99)00040-X

Goldstein, M. C. (2012). Abundance and Ecological Implications of Microplastic Debris in the North Pacific Subtropical Gyre. University of California, San Diego, CA.

Hall, N. M., Berry, K. L. E., Rintoul, L., and Hoogenboom, M. O. (2015). Microplastic ingestion by scleractinian corals. Mar. Biol. 162, 725-732. doi: 10.1007/s00227-015-2619-7

Hidalgo-Ruz, V., Gutow, L., Thompson, R. C., and Thiel, M. (2012). Microplastics in the marine environment: a review of the methods used for identification and quantification. Environ. Sci. Technol. 46, 3060-3075. doi: 10.1021/es2031505

Houlbreque, F., and Ferrier-Pages, C. (2009). Heterotrophy in tropical scleractinian corals. Biol. Rev. 84, 1-17. doi: 10.1111/j.1469-185X.2008.00058.x

Isobe, A., Uchida, K., Tokai, T., and Iwasaki, S. (2015). East Asian seas: a hot spot of pelagic microplastics. Mar. Pollut. Bull. 101, 1-6. doi: 10.1016/j.marpolbul.2015.10.042

Ivar do Sul, J. A., Costa, M. F., Silva-Cavalcanti, J. S., and Araújo, M. C. B. (2014). Plastic debris retention and exportation by a mangrove forest patch. Mar. Pollut. Bull. 78, 252-257. doi: 10.1016/j.marpolbul.2013.11.011

Jambeck, J. R., Geyer, R., Wilcox, C., Siegler, T. R., Perryman, M., Andrady, A. L., et al. (2015). Plastic waste inputs from land into the ocean. Science 347, 768-771. doi: $10.1126 /$ science. 1260352

\section{SUPPLEMENTARY MATERIAL}

The Supplementary Material for this article can be found online at: https://www.frontiersin.org/articles/10.3389/fmars. 2017.00333/full\#supplementary-material

Kukulka, T., Proskurowski, G., Morét-Ferguson, S., Meyer, D. W., and Law, K. L. (2012). The effect of wind mixing on the vertical distribution of buoyant plastic debris. Geophys. Res. Lett. 39, 1-6. doi: 10.1029/2012GL0 51116

Law, K. L., Morét-Ferguson, S. E., Maximenko, N., Proskurowski, G., Peacock, E. E., Hafner, J., et al. (2010). Plastic accumulation in the North Atlantic Subtropical Gyre. Science 329, 1185-1188. doi: 10.1126/science.11 92321

Lebreton, L. C. M., van der Zwet, J., Damsteeg, J.-W., Slat, B., Andrady, A., and Reisser, J. (2017). River plastic emissions to the world's oceans. Nat. Commun. 8:15611. doi: 10.1038/ncomms15611

Martinez-Ribes, L., Basterretxea, G., Palmer, M., and Tintoré, J. (2007). Origin and abundance of beach debris in the Balearic Islands. Sci. Mar. 71, 305-314. doi: 10.3989/scimar.2007.71n2305

Nor, N. H. M., and Obbard, J. P. (2014). Microplastics in Singapore's coastal mangrove ecosystems. Mar. Pollut. Bull. 79, 278-283. doi: 10.1016/j.marpolbul.2013.11.025

Østerhus, S., Turrell, W. R., Jónsson, S., and Hansen, B. (2005). Measured volume, heat, and salt fluxes from the Atlantic to the Arctic Mediterranean. Geophys. Res. Lett. 32, 1-4. doi: 10.1029/2004GL0 22188

Pedrotti, M. L., Petit, S., Elineau, A., Bruzaud, S., Crebassa, J.-C., Dumontet, B., et al. (2016). Changes in the floating plastic pollution of the Mediterranean Sea in relation to the distance to land. PLoS ONE 11:e0161581. doi: 10.1371/journal.pone.0161581

Ruiz-Orejón, L. F., Sardá, R., and Ramis-Pujol, J. (2016). Floating plastic debris in the Central and Western Mediterranean Sea. Mar. Environ. Res. 120, 136-144. doi: 10.1016/j.marenvres.2016.08.001

Setälä, O., Magnusson, K., Lehtiniemi, M., and Norén, F. (2016). Distribution and abundance of surface water microlitter in the Baltic Sea: a comparison of two sampling methods. Mar. Pollut. Bull. 110, 177-183. doi: 10.1016/j.marpolbul.2016.06.065

Smeed, D. A. (2004). Exchange through the Bab El Mandab. Deep Sea Res. II Top. Stud. Oceanogr. 51, 455-474. doi: 10.1016/j.dsr2.2003. 11.002

Sofianos, S. S. (2002). An Oceanic General Circulation Model (OGCM) investigation of the Red Sea circulation, 1. Exchange between the Red Sea and the Indian Ocean. J. Geophys. Res. 107:3196. doi: 10.1029/2001JC001184

Suaria, G., Avio, C. G., Mineo, A., Lattin, G. L., Magaldi, M. G., Belmonte, G., et al. (2016). The Mediterranean Plastic Soup: synthetic polymers in mediterranean surface waters. Sci. Rep. 6:37551. doi: 10.1038/srep37551

Tranter, D. J., and George, J. (1969). Zooplankton abundance at Kavaratti and Kalpeni Atolls in the Laccadives. Mar. Biol. Assoc. India 1969, 239-259.

Van der Hal, N., Ariel, A., and Angel, D. L. (2017). Exceptionally high abundances of microplastics in the Oligotrophic israeli mediterranean coastal waters. Mar. Pollut. Bull. 116, 151-155. doi: 10.1016/j.marpolbul.2016.12.052

Yahel, G., Post, A. F., Fabricius, K., Marie, D., Vaulot, D., and Genin, A. (1998). Phytoplankton distribution and grazing near coral reefs. Limnol. Oceanogr. 43, 551-563. doi: 10.4319/lo.1998.43.4.0551

Conflict of Interest Statement: The authors declare that the research was conducted in the absence of any commercial or financial relationships that could be construed as a potential conflict of interest.

Copyright (๐ 2017 Martí, Martin, Cózar and Duarte. This is an open-access article distributed under the terms of the Creative Commons Attribution License (CC BY). The use, distribution or reproduction in other forums is permitted, provided the original author(s) or licensor are credited and that the original publication in this journal is cited, in accordance with accepted academic practice. No use, distribution or reproduction is permitted which does not comply with these terms. 